\title{
ARTICLE
}

Clinical Research

\section{Very low calorie diets are associated with transient ventricular impairment before reversal of diastolic dysfunction in obesity}

\author{
Jennifer J. Rayner $\mathbb{1}^{1} \cdot$ Ines Abdesselam ${ }^{1} \cdot$ Mark A. Peterzan $^{1} \cdot$ Ioannis Akoumianakis $^{2} \cdot$ Nadia Akawi $^{2} \cdot$ \\ Charalambos Antoniades ${ }^{2} \cdot$ Jeremy W. Tomlinson ${ }^{3} \cdot$ Stefan Neubauer $^{1} \cdot$ Oliver J. Rider $^{1}$
}

Received: 29 August 2018 / Revised: 15 October 2018 / Accepted: 26 October 2018 / Published online: 21 November 2018

(c) The Author(s) 2018. This article is published with open access

\begin{abstract}
Objectives Very low calorie diets (VLCDs) are effective at clearing hepatic steatosis and improving insulin sensitivity. Whilst long-term weight loss is beneficial to the cardiovascular system, the acute elevation in fatty acids during caloric restriction is potentially detrimental to cardiac metabolism and function. We sought to investigate any cardiovascular changes occurring over the course of a modern VLCD regime, alongside the expected peripheral metabolic improvements. Methods 25 obese volunteers (BMI $36.8 \pm 5.8 \mathrm{~kg} / \mathrm{m}^{2}$ ) underwent magnetic resonance imaging, echocardiography, metabolic profiling, and bio-impedance analysis before 1 and 8 weeks following a VLCD ( $800 \mathrm{kcal} /$ day). Results were compared to 15 age- and sex-matched controls.

Results After 1 week of VLCD, despite only modest weight loss, significant drops occurred in liver fat and insulin resistance (HOMA-IR; by 14-50\%, all $p<0.01$ ). In contrast, myocardial triglyceride content (MTGC) increased (by $48 \%, p=0.030$ ), and was associated with deterioration in both systolic (LVEF by $4 \%, p=0.041)$ and diastolic function $\left(e / e^{\prime} 8.6 \pm 1.4\right.$ to $9.4 \pm 1.7, p=0.019)$. Aortic stiffness also increased by $35 \%(p=0.015)$.

At 8 weeks, liver steatosis and visceral fat were lower than baseline (by 20-55\%, $p<0.001$ ), and peripheral metabolic improvements continued. MTGC also fell to below baseline $(1.5 \pm 0.6$ vs $2.1 \pm 1 \%, p=0.05)$ with improved myocardial function (ele $8.6 \pm 1.4$ to $7.5 \pm 1.5, p=0.003)$.

Conclusions Whilst VLCDs result in dramatic improvements in insulin resistance, they are associated with transient but significant cardiovascular functional decline, which may have an impact on those with the coexisting cardiac disease. However, after 8 weeks, the diet was associated with normalisation of cardiac function, suggesting they may form a potential therapeutic intervention for diastolic dysfunction in obesity and diabetes.
\end{abstract}

\section{Introduction}

In the 1970s, severely calorie-restricted diets became a commonplace means of losing weight. However, in 1978 a Food and Drug Administration investigation of 800,000

Jennifer J. Rayner

jenny.rayner@cardiov.ox.ac.uk

1 Oxford Centre for Clinical Magnetic Resonance Research, Division of Cardiovascular Medicine, Radcliffe Department of Medicine, University of Oxford, Oxford, UK

2 Division of Cardiovascular Medicine, Radcliffe Department of Medicine, University of Oxford, Oxford, UK

3 Oxford Centre for Diabetes, Endocrinology and Metabolism (OCDEM), NIHR Oxford Biomedical Research Centre, University of Oxford, Oxford, UK patients adhering to liquid protein very low calorie diets (VLCDs) reported 46 deaths [1]. Following this, sales of liquid replacement meals plummeted and 'crash' dieting was widely regarded as dangerous.

With increasing rates of obesity and associated type II diabetes, VLCDs have again become popular. However, modern VLCD plans provide nutritionally balanced meal replacement, and have shifted focus towards effectively reversing type II diabetes [2]. Profound caloric restriction leads to rapid reductions in liver fat, driven by hepatic lipolysis and reduced ectopic triglyceride deposition [3]. This enables more efficient fatty acid (FA) oxidation, and improved insulin sensitivity in the short term. In the medium term, VLCDs can reduce pancreatic fat and increase insulin secretion, as well as improve the insulin sensitivity of skeletal muscle [4]. The recently published DiRECT trial highlights the effectiveness of these diets [5], showing at 
12 months almost half of the participants achieving diabetes remission.

Whilst the combination of improved insulin sensitivity and weight loss should be beneficial to the cardiovascular system [6], this may well not be the case due to the elevation in circulating free fatty acid (FFA) levels that occurs during rapid mobilisation of fat stores. Acute elevation of FFA levels has been shown to impair vascular function in humans [7], and lead to myocardial lipid accumulation and dysfunction in animals [8, 9], with a 3-day extreme VLCD (471 kcal/day) in humans also resulting in impaired diastolic function [10, 11].

The effects of the contemporary VLCDs on myocardial and vascular function in a real-world setting are yet to be established, but are an important consideration given both the historical context of increased cardiovascular risk with VLCDs, and the burgeoning worldwide prevalence of cardiac dysfunction associated with obesity. With these concerns in mind, we sought to investigate in a healthy obese population whether any changes in cardiovascular metabolism and function occur over the course of a modern 8-week VLCD regime, and seek to find whether these dietary interventions have the potential for treatment of obesityrelated cardiac dysfunction.

\section{Methods}

Forty volunteers were recruited by poster advertisement, of whom 25 were obese and were allocated to the VLCD, and the remainder were normal weight control subjects. Inclusion criteria were age $>18$ years, BMI $>30 \mathrm{~kg} / \mathrm{m}^{2}$ (VLCD group) or $<25 \mathrm{~kg} / \mathrm{m}^{2}$ (control). Exclusion criteria were insulin therapy for diabetes, current or previous history of coronary disease, systolic heart failure, pregnancy, and standard contraindications to magnetic resonance (MR) scanning. The local ethics committee approved the study (REC SC/15/004), and informed written consent was obtained.

\section{Anthropomorphic and metabolic assessment}

Body composition was analysed by bio-impedance (InBody 770, InBody Co. Ltd., South Korea). Non-invasive blood pressure was measured manually (average of 3 supine measurements, Carescape V100, GE Healthcare, Chicago, IL, USA). Fasting venous blood was drawn for circulating biomarkers; glucose, cholesterol, triglycerides, and BNP were analysed by the Oxford University Hospitals NHS Trust laboratory according to standard clinical protocols. FFAs and $\beta$-hydroxybutyrate were measured using commercially available colorimetric assay kits $(\mathrm{CV}<6 \%$ and $<4 \%$, respectively; Cayman Chemical, MI, USA).
To assess insulin resistance, a mixed meal tolerance test was performed at baseline and 8 weeks (37 g carbohydrate, $12 \mathrm{~g}$ protein, and $12 \mathrm{~g}$ fat $(200 \mathrm{ml}$ Fortisip drink, Nutricia, Schiphol, The Netherlands)), with venous glucose and insulin drawn additionally at 30, 60, and $120 \mathrm{~min}$. Insulin resistance was calculated both using the HOMA-IR model at all 3 time-points ((fasting glucose $\times$ fasting insulin)/22.5), and the Matsuda index at baseline and 8 weeks $(10,000 /$ $\sqrt{ }(($ fasting glucose $\times$ fasting insulin $) \times($ mean glucose $\times$ mean insulin during meal tolerance test))).

\section{Magnetic resonance imaging}

Left ventricular geometry and systolic function, liver fat, myocardial triglyceride content (MTGC), myocardial energetics (PCr/ATP, 1 and 8 weeks only), regional aortic elastic function, epicardial and abdominal visceral fat were all assessed using a combination of multiparametric MRI and multinuclear spectroscopy (3 Tesla Trio, Siemens, Erlangen, Germany) as described below.

\section{Left ventricular geometry and function}

LV imaging was retrospectively cardiac-gated and acquired during end-expiratory breath-hold. LV mass, volumes, and ejection fraction were calculated from manual endocardial and epicardial contours (CVI42, Circle Cardiovascular Imaging Inc, Calgary, Canada) [12]. LV mass and EDV are presented indexed to height ${ }^{1.7}$ as is appropriate for this adult population [13]. Strain and strain rates were derived from tissue tracking [14].

\section{Myocardial triglyceride content}

Myocardial ${ }^{1} \mathrm{H}-\mathrm{MR}$ spectra were obtained from the interventricular septum [15]. Water-suppressed spectra were acquired to measure MTGC, and spectra without water suppression were used as an internal standard. Spectra were analysed using Matlab and the AMARES algorithm [16].

\section{Myocardial energetics}

PCr/ATP was derived from a cardiac-gated fully relaxed 1D-CSI acquisition using a $10 \mathrm{~cm}$ loop transmit-receive ${ }^{31} \mathrm{P}$ surface coil (Pulse Teq, Chobham, UK). The ${ }^{31} \mathrm{P}$ coil was matched for each subject using a radio frequency sweeper (Morris Instruments Inc, Ottawa, Canada). In-house script within Matlab was used for analysis.

\section{Abdominal visceral fat mass}

Abdominal visceral fat area was measured with a $5 \mathrm{~mm}$ transverse slice at the level of the 5th lumbar vertebral body, 
using a water-suppressed turbo spin echo (TSE) sequence, and analysed manually [16].

\section{Liver fat content}

Hepatic fat was calculated using the Dixon method, and analysed on custom software [17].

\section{Epicardial fat volume}

Epicardial fat volume was measured by manual contouring of cardiac short axis images, by a blinded investigator (IA) as previously published [18].

\section{Aortic distensibility}

Regional aortic distensibility (AD) was assessed using an SSFP cine sequence at 2 levels: (1) the ascending thoracic aorta and (2) in the abdomen $12 \mathrm{~cm}$ below this slice [7]. During the acquisition of the images, a brachial BP was recorded. AD $\left(\mathrm{mmHg}^{-1}\right)$ was calculated as [(Aortic Area $\max -$ Area $\min ) /($ Area $\min ) /$ pulse pressure $] \times 1000$.

\section{Echocardiography}

Diastolic functional parameters were assessed with standard 2D transthoracic echocardiography (Philips Epiq system). These were analysed using Xcelera reporting software (Philips Healthcare). Average E/e' values are presented.

\section{Very low calorie diet}

The 25 obese volunteers followed a supervised VLCD (800 kcal per day; $59 \%$ carbohydrate, $26 \%$ protein, $13 \%$ fat, $3 \%$ fibre; replacement diet programme, Counterweight Ltd., UK) for 8 weeks before gradual meal reintroduction. Antihypertensive therapy was discontinued at the start of the diet intervention. Volunteers were advised to continue current levels of physical activity, and increase fluid intake with water or calorie-free fluids to ensure adequate hydration.

\section{Statistics}

Statistical analysis was performed using commercial software (SPSS, Chicago, USA). All data is presented as mean \pm standard deviation. Homogeneity of distribution was confirmed before determination of statistical significance, either by Chi-squared tests in the case of nominal data, Student's $t$ tests for continuous data (independent for comparison of baseline characteristics), or repeated measures ANOVA (for comparison within individuals at the 3 time points) with the Greenhouse-Geisser correction, with post-hoc tests using the Bonferroni correction. Pearson's correlation models were used where relevant. Values of $p<$ 0.05 were considered as statistically significant.

\section{Results}

Twenty-eight individual volunteers were initially screened for the VLCD study, of whom 1 was excluded due to a new diagnosis of atrial fibrillation, 1 was excluded due to severe claustrophobia, and 1 was unable to tolerate the MRI scans due to body habitus. Of the 25 recruited VLCD volunteers, the majority were female (17/25) (Table 1). Two volunteers withdrew by 1 week, and a further 2 by 8 weeks-there were no significant differences in characteristics in these individuals to those who completed the study (Fig. 1).

\section{Baseline}

\section{Anthropometric and metabolic characteristics}

VLCD volunteers and controls were well matched for age (study group $49 \pm 14$ years, controls $45 \pm 17$ years, $p=$ 0.410 ) and sex (study group $32 \%$ male, controls $40 \%$ male, $p=0.717)$. As expected, the average BMI of the volunteers was higher than controls $\left(36.8 \pm 5.8\right.$ vs $24.0 \pm 2.4 \mathrm{~kg} / \mathrm{m}^{2}$, $p<0.001$ ). Liver fat was also significantly higher (VLCD $7.4 \pm 6.3 \%$ vs $0.9 \pm 0.6 \%, p<0.001)$, and above the threshold for diagnosis of non-alcoholic fatty liver disease $(>5 \%)$ in 15 individuals. On average, blood pressure in the study group was systolic $135 \pm 20 \mathrm{mmHg}$, and diastolic $89 \pm 11 \mathrm{mmHg}$, with both values significantly higher than controls $(p<0.01$, Table 1$)$.

Although fasting glucose $(5.4 \pm 0.9 \mathrm{mmol} / \mathrm{l})$, total cholesterol $(5.4 \pm 1.0 \mathrm{mmol} / \mathrm{l})$, and plasma triglycerides $(1.6 \pm$ $0.7 \mathrm{mmol} / \mathrm{l}$ ) were within the normal range, they were all higher than controls (all $p<0.05$, Table 1). The obese VLCD group was significantly more insulin resistant compared to controls (HOMA-IR $4.3 \pm 5.1$ vs $1.2 \pm 0.5, p=$ 0.029).

\section{Baseline cardiac function and metabolism}

The obese VLCD group had higher LV mass (by $15 \%$ when indexed to height, $p=0.015)$, two-fold higher myocardial triglyceride levels $(p=0.003)$ and reduced myocardial energetics (PCr/ATP by $14 \%, p=0.003$ ). There was evidence of subclinical changes in systolic function with reduced radial strain (by $19 \%, p=0.002$ ). Diastolic function was significantly more impaired in the obese VLCD group at baseline (average $E / e^{\prime} 8.4 \pm 1.4$ vs $7.6 \pm 1.3, p=$ 0.022). Importantly, FFA levels correlated with MTGC at baseline ( $r=0.479, p=0.028$, Fig. 2 ). 
Table 1 Baseline demographics and anthropomorphic data

\begin{tabular}{|c|c|c|c|}
\hline & $\begin{array}{l}\text { Normal } \\
\text { controls } \\
n=15\end{array}$ & $\begin{array}{l}\text { Study } \\
\text { population } \\
n=25\end{array}$ & $p$ \\
\hline \multicolumn{4}{|l|}{ Anthropomorphic } \\
\hline BMI $\left(\mathrm{kg} / \mathrm{m}^{2}\right)$ & $24.0 \pm 2.4$ & $36.8 \pm 5.8$ & $<0.001$ \\
\hline Age (years) & $45 \pm 17$ & $49 \pm 14$ & 0.410 \\
\hline Male & 6 & 8 & 0.717 \\
\hline $\begin{array}{l}\text { Systolic blood pressure } \\
(\mathrm{mmHg})\end{array}$ & $121 \pm 15$ & $136 \pm 19$ & 0.008 \\
\hline $\begin{array}{l}\text { Diastolic blood pressure } \\
(\mathrm{mmHg})\end{array}$ & $77 \pm 11$ & $89 \pm 11$ & 0.004 \\
\hline \multicolumn{4}{|l|}{ Metabolic parameters } \\
\hline Total cholesterol $(\mathrm{mmol} / \mathrm{l})$ & $4.6 \pm 1.0$ & $5.4 \pm 1.0$ & 0.017 \\
\hline HDL cholesterol (mmol/l) & $1.4 \pm 0.3$ & $1.6 \pm 1.0$ & 0.479 \\
\hline LDL cholesterol $(\mathrm{mmol} / \mathrm{l})$ & $2.8 \pm 0.9$ & $3.1 \pm 0.8$ & 0.077 \\
\hline Triglycerides (mmol/l) & $1.0 \pm 0.5$ & $1.6 \pm 0.7$ & 0.003 \\
\hline Glucose $(\mathrm{mmol} / \mathrm{l})$ & $4.8 \pm 0.3$ & $5.4 \pm 0.9$ & 0.011 \\
\hline Insulin $(\mathrm{mmol} / \mathrm{l})$ & $35 \pm 13$ & $94 \pm 48$ & 0.019 \\
\hline HOMA-IR & $1.2 \pm 0.5$ & $4.3 \pm 5.1$ & 0.029 \\
\hline \multicolumn{4}{|l|}{ Medication } \\
\hline Antihypertensive therapy & 2 & 4 & 0.757 \\
\hline ACE inhibitor & 1 & 2 & 0.834 \\
\hline $\begin{array}{l}\text { Angiotensin receptor } \\
\text { blocker }\end{array}$ & 0 & 1 & 0.418 \\
\hline Calcium channel blocker & 2 & 1 & 0.308 \\
\hline Statin & 1 & 3 & 0.545 \\
\hline Metformin & 0 & 2 & 0.246 \\
\hline \multicolumn{4}{|l|}{ Body fat distribution } \\
\hline Body fat mass (kg) & $16 \pm 7$ & $45 \pm 13$ & $<0.001$ \\
\hline Body fat percentage $(\%)$ & $23 \pm 11$ & $43 \pm 8$ & $<0.001$ \\
\hline $\begin{array}{l}\text { Abdominal visceral fat area } \\
\left(\mathrm{cm}^{2}\right)\end{array}$ & $56 \pm 45$ & $162 \pm 81$ & $<0.001$ \\
\hline Liver fat $(\%)$ & $0.9 \pm 0.6$ & $7.4 \pm 6.3$ & 0.001 \\
\hline Epicardial fat $\left(\mathrm{cm}^{3}\right)$ & $38 \pm 15$ & $102 \pm 33$ & $<0.001$ \\
\hline $\begin{array}{l}\text { Myocardial triglyceride } \\
\text { content }(\%)\end{array}$ & $1.0 \pm 0.7$ & $2.2 \pm 1.1$ & 0.003 \\
\hline \multicolumn{4}{|l|}{ LV geometry } \\
\hline $\begin{array}{l}\text { LV end-diastolic volume } \\
(\mathrm{ml})\end{array}$ & $146 \pm 26$ & $156 \pm 27$ & 0.267 \\
\hline $\begin{array}{l}\text { LV EDV indexed to height } \\
\left(\mathrm{ml} / \mathrm{m}^{1.7}\right)\end{array}$ & $60 \pm 9$ & $64 \pm 9$ & 0.211 \\
\hline LV mass (g) & $98 \pm 20$ & $114 \pm 27$ & 0.046 \\
\hline $\begin{array}{l}\text { LV mass indexed to height } \\
\left(\mathrm{g} / \mathrm{m}^{1.7}\right)\end{array}$ & $40 \pm 6$ & $46 \pm 9$ & 0.015 \\
\hline LV mass-to-volume ratio & $0.66 \pm 0.06$ & $0.74 \pm 0.15$ & 0.056 \\
\hline \multicolumn{4}{|l|}{ Myocardial energetics } \\
\hline Myocardial PCr/ATP & $2.2 \pm 0.2$ & $1.9 \pm 0.3$ & 0.003 \\
\hline \multicolumn{4}{|l|}{ LV systolic function } \\
\hline LV ejection fraction (\%) & $65 \pm 7$ & $66 \pm 5$ & 0.408 \\
\hline Peak radial strain $(\%)$ & $52 \pm 10$ & $42 \pm 8$ & 0.002 \\
\hline
\end{tabular}

Table 1 (continued)

\begin{tabular}{llll}
\hline & $\begin{array}{l}\text { Normal } \\
\text { controls } \\
n=15\end{array}$ & $\begin{array}{l}\text { Study } \\
\text { population } \\
n=25\end{array}$ & $p$ \\
\hline $\begin{array}{l}\text { Peak circumferential } \\
\text { strain (\%) }\end{array}$ & $-20 \pm 2$ & $-20 \pm 2$ & 0.275 \\
$\quad \begin{array}{l}\text { Peak longitudinal } \\
\text { strain (\%) }\end{array}$ & $-16 \pm 2$ & $-16 \pm 2$ & 0.831 \\
LV diastolic function & & & \\
$\quad$ LV E/e' & $7.6 \pm 1.3$ & $8.6 \pm 1.4$ & $\mathbf{0 . 0 2 2}$ \\
$\quad \begin{array}{l}\text { Peak radial diastolic strain } \\
\text { rate (1/s) }\end{array}$ & $-3.7 \pm 1.1$ & $-2.7 \pm 1.5$ & $\mathbf{0 . 0 2 0}$ \\
Aortic distensibility (mmHg) & & & \\
$\quad \begin{array}{l}\text { Ascending aorta } \\
\text { Distal descending aorta }\end{array}$ & $4.1 \pm 2.7$ & $5.4 \pm 3.8$ & 0.284 \\
\hline
\end{tabular}

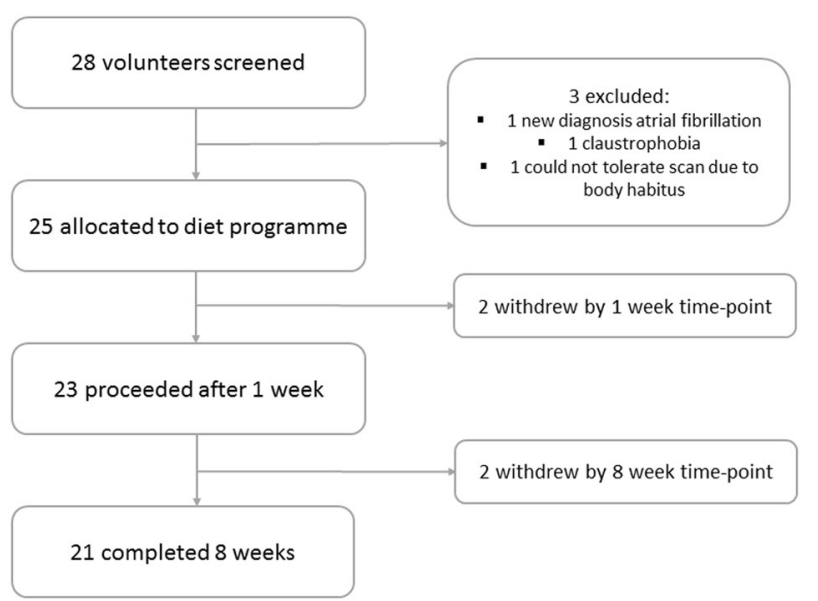

Fig. 1 CONSORT diagram demonstrating the study population

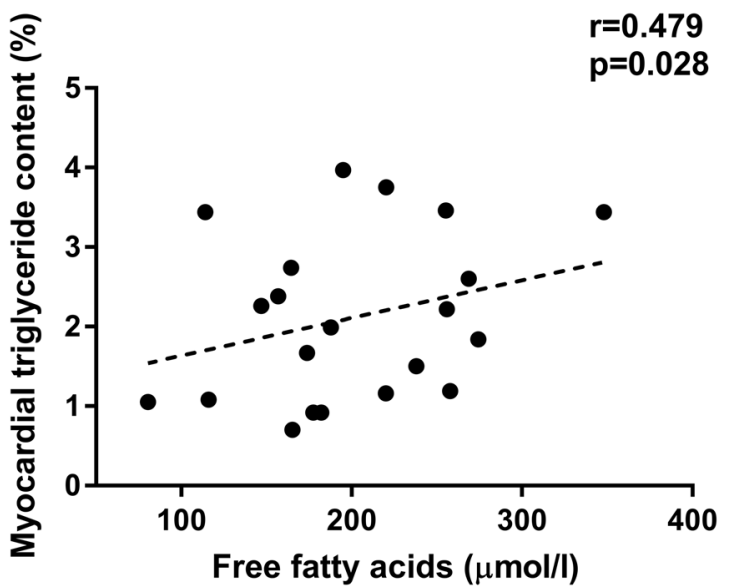

Fig. 2 Myocardial triglyceride content correlates with circulating free fatty acids at baseline 


\section{Aortic elastic function}

Although AD was similar to controls in the ascending aorta $(p=0.28)$, abdominal aortic elastic function was significantly impaired (by $33 \%)$ in the obese group $(4.9 \pm 3.8$ vs $\left.7.3 \pm 2.4 \mathrm{mmHg}^{-1}, p=0.026\right)$.
The effects of 1 week of VLCD

Following 7 days of VLCD, there were small but significant reductions in BMI $\left(1.3 \pm 0.5 \mathrm{~kg} / \mathrm{m}^{2}\right)$, and most fat depots (Table 2). A larger relative fall in hepatic fat occurred $(31 \pm 24 \%, \quad p<0.001, \quad$ Fig. 3a), with significant
Table 2 Findings at 1 and 8 weeks compared to baseline

\begin{tabular}{|c|c|c|c|}
\hline & $\begin{array}{l}\text { Baseline } \\
n=25\end{array}$ & $\begin{array}{l}1 \text { week } \\
n=23\end{array}$ & $\begin{array}{l}8 \text { weeks } \\
n=21\end{array}$ \\
\hline \multicolumn{4}{|l|}{ Anthropometric } \\
\hline BMI $\left(\mathrm{kg} / \mathrm{m}^{2}\right)$ & $36.8 \pm 5.8$ & $35.1 \pm 5.8 * *$ & $32.3 \pm 5.8 * * \ddagger$ \\
\hline Body fat mass (kg) & $45 \pm 13$ & $42 \pm 14^{* *}$ & $35 \pm 14 * * \ddagger$ \\
\hline Body fat percentage (\%) & $43 \pm 8$ & $40 \pm 9^{*}$ & $36 \pm 10^{* * *}$ \\
\hline Systolic blood pressure (mmHg) & $136 \pm 19$ & $128 \pm 14^{*}$ & $124 \pm 12 *$ \\
\hline Diastolic blood pressure $(\mathrm{mmHg})$ & $89 \pm 11$ & $87 \pm 16$ & $80 \pm 10$ \\
\hline \multicolumn{4}{|l|}{ Metabolic parameters } \\
\hline Total cholesterol (mmol/l) & $5.4 \pm 1.0$ & $4.5 \pm 1.0 * *$ & $4.6 \pm 1.0 * *$ \\
\hline Triglycerides (mmol/l) & $1.6 \pm 0.7$ & $1.2 \pm 0.6 * *$ & $1.4 \pm 0.9$ \\
\hline Beta-hydroxybutyrate (mmol/l) & $0.25 \pm 0.10$ & $0.55 \pm 0.35^{* *}$ & $0.46 \pm 0.23 * *$ \\
\hline Free fatty acids $(\mu \mathrm{mol} / \mathrm{l})$ & $197 \pm 71$ & $284 \pm 78 * *$ & $314 \pm 143 * *$ \\
\hline Beta natriuretic peptide $(\mathrm{mmol} / \mathrm{l})$ & $4.8 \pm 2.8$ & $3.7 \pm 1.7$ & $5.5 \pm 3.0 *$ \\
\hline Glucose (mmol/l) & $5.4 \pm 0.9$ & $4.7 \pm 0.9 * *$ & $4.8 \pm 0.6^{* *}$ \\
\hline HOMA-IR & $4.3 \pm 5.1$ & $1.7 \pm 1.4^{*}$ & $1.3 \pm 0.7 *$ \\
\hline Matsuda index & $19 \pm 13$ & - & $24 \pm 12 * *$ \\
\hline \multicolumn{4}{|l|}{ Body fat distribution } \\
\hline Liver fat $(\%)$ & $7.4 \pm 6.3$ & $5.5 \pm 5.0 * *$ & $3.3 \pm 3.0^{* \dagger}$ \\
\hline Myocardial triglyceride content $(\%)$ & $2.2 \pm 1.1$ & $3.1 \pm 1.7 *$ & $1.5 \pm 0.6^{* \dagger}$ \\
\hline Epicardial fat $\left(\mathrm{cm}^{3}\right)$ & $102 \pm 33$ & $91 \pm 27^{*}$ & $86 \pm 29 * * *$ \\
\hline Abdominal visceral fat area $\left(\mathrm{cm}^{2}\right)$ & $162 \pm 81$ & $153 \pm 93$ & $102 \pm 53 * * *$ \\
\hline \multicolumn{4}{|l|}{ LV geometry and function } \\
\hline LV end-diastolic volume (ml) & $156 \pm 27$ & $144 \pm 26^{* *}$ & $151 \pm 27 *$ \\
\hline LV EDV indexed to height $\left(\mathrm{ml} / \mathrm{m}^{1.7}\right)$ & $63 \pm 9$ & $58 \pm 8 * *$ & $61 \pm 8^{*}$ \\
\hline LV ejection fraction $(\%)$ & $66 \pm 5$ & $62 \pm 6^{*}$ & $64 \pm 5$ \\
\hline LV mass $(\mathrm{g})$ & $114 \pm 27$ & $110 \pm 23$ & $107 \pm 23 *$ \\
\hline LV mass indexed to height $\left(\mathrm{g} / \mathrm{m}^{1.7}\right)$ & $46 \pm 10$ & $44 \pm 8^{*}$ & $43 \pm 7$ \\
\hline \multicolumn{4}{|l|}{ LV strain analysis } \\
\hline Peak radial strain $(\%)$ & $42 \pm 9$ & $45 \pm 11^{*}$ & $48 \pm 11$ \\
\hline Peak circumferential strain $(\%)$ & $-20 \pm 2$ & $-19 \pm 2 * *$ & $-19 \pm 2$ \\
\hline Peak longitudinal strain $(\%)$ & $-16 \pm 1$ & $-15 \pm 2$ & $-15 \pm 3$ \\
\hline Peak radial diastolic strain rate $(1 / \mathrm{s})$ & $-2.7 \pm 1.0$ & $-3.2 \pm 0.8$ & $-3.2 \pm 1.0 *$ \\
\hline LV average $E / e^{\prime}$ & $8.6 \pm 1.4$ & $9.4 \pm 1.7 * *$ & $7.5 \pm 1.5^{* *}$ \\
\hline Myocardial PCr/ATP & $1.9 \pm 0.3$ & - & $2.2 \pm 0.2 *$ \\
\hline \multicolumn{4}{|l|}{ Aortic distensibility } \\
\hline Ascending aorta & $5.4 \pm 3.8$ & $4.3 \pm 3.4 * *$ & $5.8 \pm 4.6$ \\
\hline Distal descending aorta & $4.1 \pm 2.5$ & $3.9 \pm 2.1$ & $5.0 \pm 2.8$ \\
\hline
\end{tabular}

${ }^{*} p<0.05$ compared to baseline

$* * p<0.01$ compared to baseline

${ }^{\dagger} p<0.05$ compared to normal controls (Week 8 data only)

${ }^{\ddagger} p<0.01$ compared to normal controls (Week 8 data only) 

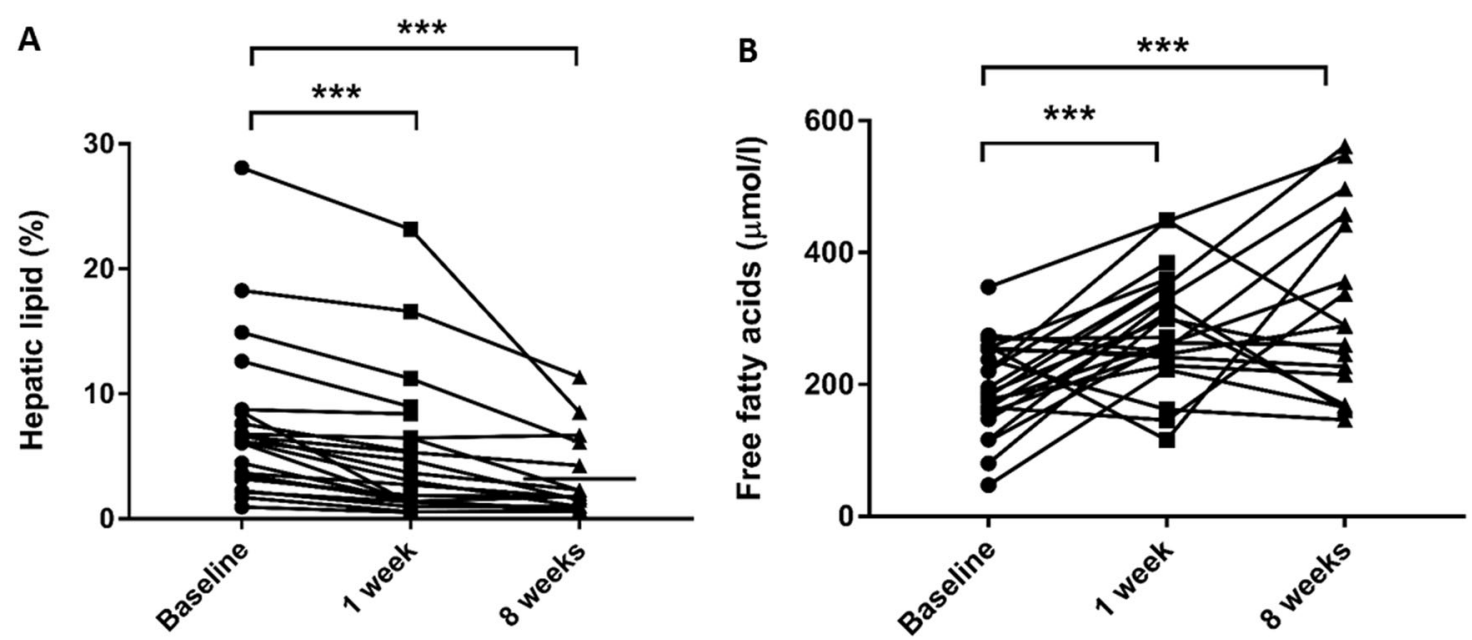

Fig. 3 Hepatic lipid (a) and free fatty acids (b) at baseline, 1 and 8 weeks after initiation of the very low calorie diet $(* p<0.05, * * * p<0.001)$
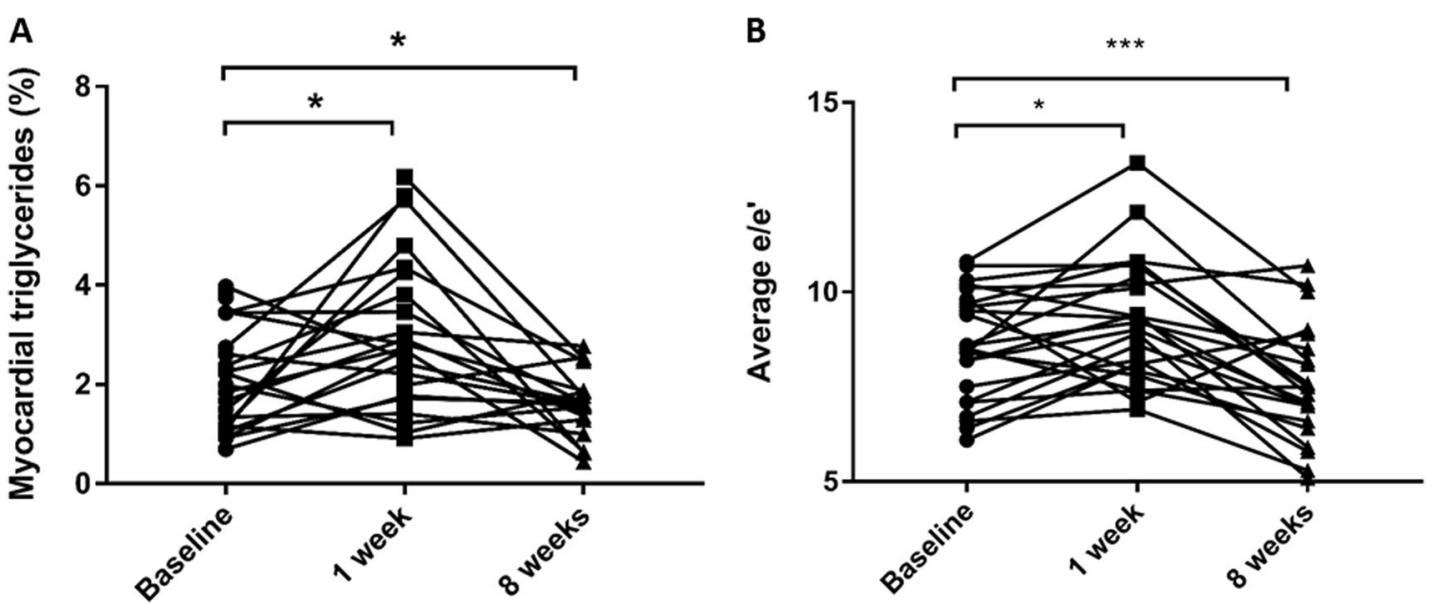

Fig. 4 Myocardial triglycerides (a) and diastolic function (b) at baseline, 1 and 8 weeks after the initiation of the very low calorie diet $(* p<0.05$, $* * * p<0.001$ )

improvements in fasting glucose (by $13 \pm 14 \%$ ), and insulin sensitivity (HOMA-IR by $42 \pm 26 \%$, all $p<0.01$, Table 2 ). Despite the withdrawal of antihypertensive medication, systolic blood pressure fell (by $6 \pm 9$ to $128 \pm 14 \mathrm{mmHg}$, $p=0.035$ ).

Blood $\beta$-hydroxybutyrate levels increased (from $0.25 \pm$ 0.10 to $0.55 \pm 0.35 \mathrm{mmol} / \mathrm{l}, p=0.002$ ), supporting adherence to the diet programme, and circulating levels of FAs rose 55\% during the first week of VLCD $(p=0.017$, Fig. 3b). In contrast to other fat depots, MTGC increased by $50 \%$ (from $2.1 \pm$ $1.1 \%$ to $3.1 \pm 1.7 \%, p=0.030$, Fig. $4 \mathrm{a}$ ). At this time-point, there was a deterioration in both LV systolic function (LVEF $66 \pm 5 \%$ to $62 \pm 6 \%, p=0.041)$, and diastolic function (average E/e' $8.6 \pm 1.4$ to $9.4 \pm 1.7, p=0.019$, Fig. $4 \mathrm{~b}$ ). There was a trend for the change in MTGC to correlate with change in both systolic (LVEF, $r=-0.43, p=0.08$ ) and diastolic function $(p=0.056)$. Suggesting no change in circulating volume, blood haematocrit did not change from baseline
$(0.422 \pm 0.038$ compared to $0.428 \pm 0.38, p=0.216)$. BNP levels remained unchanged during this initial period $(4.8 \pm 2.8$ vs $3.7 \pm 1.7 \mathrm{pg} / \mathrm{ml}$, Table 2 ).

Furthermore, aortic elastic function was reduced from baseline in the ascending aorta $(4.3 \pm 3.4$ from $5.4 \pm$ $3.8 \mathrm{mmHg}^{-1}, p=0.009$ ).

In summary, after 1 week of VLCD, despite significant metabolic benefits, the already impaired cardiovascular system in obesity deteriorated further, with elevation in MTGC, reduced left ventricular systolic and diastolic function, and further increase in aortic stiffness.

\section{The effect of 8 weeks of VLCD}

After 8 weeks $(n=21$, average timeframe $53 \pm 13$ days; all results in Table 2), total body weight continued to fall (by $12 \%$ from baseline, $p<0.01$ ), with ongoing improvements in insulin sensitivity and lipid profile (Table 2). 
Final blood pressure values were lower than baseline (systolic $124 \pm 12 \mathrm{mmHg}, \quad p=0.035$; diastolic $80 \pm 10 \mathrm{mmHg}, p=0.068)$, and similar to normal values (control group systolic blood pressure $121 \pm 15 \mathrm{mmHg}, p=$ 0.192 ; diastolic $77 \pm 11 \mathrm{mmHg}, p=0.848$ ).

$\beta$-Hydroxybutyrate remained significantly elevated $(0.46 \pm 0.23 \mathrm{mmol} / \mathrm{l}$ compared to $0.25 \pm 0.10 \mathrm{mmol} / 1, p=$ 0.014 ), indicating likely continued compliance, and FFAs continued to rise (week $8277 \pm 136$ vs week $1168 \pm 61$ $\mu \mathrm{mol} / 1, p=0.018$, Fig. 3b). However, having initially increased, by 8 weeks MTGC had fallen, and were now significantly lower than baseline $(1.5 \pm 0.6 \%$ compared to $2.2 \pm 1.1 \%$ at baseline, $p=0.050$, Fig. $4 \mathrm{a}$ ). Whilst initially impaired, myocardial energetics improved over the course of the VLCD (PCr/ATP by $14 \%, p=0.021$ ) and were now similar to normal values (study group $2.2 \pm 0.2$ compared to controls $2.2 \pm 0.2, p=0.54)$.

By 8 weeks, LV geometry was improved; EDV and mass were significantly lower than baseline, and not statistically different from normal weight controls (EDV $61 \pm 8 \mathrm{ml} / \mathrm{m}^{1.7}$ compared to control group $60 \pm 9 \mathrm{ml} / \mathrm{m}^{1.7}, p=0.403 ; \mathrm{LV}$ mass $43 \pm 7 \mathrm{~g} / \mathrm{m}^{1.7}$ compared to control group $40 \pm 6 \mathrm{~g} / \mathrm{m}^{1.7}$, $p=0.222$ ). Systolic function had returned to normal ( $\mathrm{LV}$ EF $64 \pm 5 \%$ compared to $66 \pm 5 \%$ baseline, $p=0.638)$. Not only had diastolic function improved from the 1 week timepoint $\left(E / e^{\prime} 8\right.$ weeks $7.5 \pm 1.5$ vs 1 week $9.4 \pm 1.7, p<$ 0.001 ), but there was a significant improvement from baseline $\left(E / e^{\prime} 8\right.$ weeks $7.5 \pm 1.5$ vs baseline $8.6 \pm 1.4, p=$ 0.003 , Fig. 4b), with values similar to normal controls (control group $7.6 \pm 1.3, p=0.877$ ).

By 8 weeks, AD returned to baseline levels in the ascending aorta $(5.8 \pm 4.6 \mathrm{mmHg}$ compared to control $4.1 \pm$ $2.7 \mathrm{mmHg}, p=0.262$ ), but was still impaired when compared to controls (descending $5.0 \pm 2.9 \mathrm{mmHg}^{-1}$ compared to normal $7.3 \pm 2.4 \mathrm{mmHg}^{-1}, p=0.050$ ).

\section{Discussion}

There has recently been a renaissance of VLCDs as a means to reverse the metabolic consequences of obesity. The DiRECT trial, showing effectiveness in diabetes reversal [5], should undoubtedly increase their utilisation further. Despite these metabolic improvements, by elevating FFA levels VLCDs have the potential to cause cardiovascular decline. Here, we demonstrate a transient, early, and significant deterioration in cardiovascular function, with increased MTGC after 1 week of caloric restriction, in contrast to the metabolic improvements seen from the onset of the diet. Despite this early deterioration, by 8 weeks diastolic function had improved to normal values, suggesting that VLCDs may be a therapeutic option for diastolic dysfunction in diabetes and obesity.

\section{Early cardiovascular deterioration in very low calorie diet}

In this study, we highlight that successful weight loss over the course of 2 months in obesity results in substantial cardiovascular benefits. However, we show that initially, there is an increase in myocardial steatosis (by 43\%) that is accompanied by reduced LVEF, and diastolic dysfunction (with increased $\left.E / e^{\prime}\right)$. The dominant metabolic processes during profound caloric restriction are the mobilisation of triacylglycerols (TAGs) in adipose tissue and gluconeogenesis by the liver (the main source of glucose during fasting) [19]. TAG is broken down into FAs by three main lipases (adipose triglyceride lipase, hormone-sensitive lipase, and monoglyceride lipase) into FAs which then undergo beta-oxidation. The glycerol backbone of TAG is used as a gluconeogenic substrate and the expression/activation of the main gluconeogenic enzymes (PEPCK-C and G6Pase) during fasting is stimulated by glucagon. As myocardial uptake of FFA is proportional to plasma concentration [20], the relative steatosis is likely to reflect a combination of increased FFA uptake, as well as a degree of impaired intracellular FA oxidation in the context of insulin resistance.

This increase in lipid content is likely to be the underlying cause of functional deterioration, as MTGC has been previously shown to contribute to cardiac dysfunction in human obesity [14]. In addition, the fall in LV end-diastolic volume, in the context of elevated diastolic markers and absence of volume depletion, is likely to represent stiffening of the left ventricle. It is in part reassuring that BNP did not elevate at this time-point; however, this is difficult to interpret given the negative association between obesity and BNP [21] meaning that loss of fat mass itself may lead to an increase in BNP values.

There are a number of mechanisms by which impaired cardiac function can be attributed to increased levels of MTGC. In addition to being a less energy efficient substrate than glucose [22], the oversupply of FFAs beyond the oxidative capacity of the heart leads to the diversion of triglyceride down non-oxidative pathways and accumulation of lipotoxic intermediate metabolites such as ceramide and diacylglycerol. These not only further impair FFA oxidation but also worsen intracellular insulin sensitivity, alter calcium handling [23] and favour accumulation of reactive oxygen species (ROS) [24], all of which impair cardiac function [25].

There is also recent evidence to suggest that myocardial uptake of ketones is both increased in insulin resistance, and is associated with LV dysfunction, suggesting that some of the early functional changes may be related to increased ketones [26].

In a similar fashion to myocardial function, aortic elastic function demonstrates early impairment. As there is 
evidence both that raised FFAs increase ROS in arterial endothelial cells and impair endothelial function [27], and that artificial elevation of FFAs results in a similar pattern of aortic stiffness [7], it is likely that this is implicated in the vascular stiffening seen.

\section{Cardiovascular benefits after 8 weeks of VLCD}

By 8 weeks, with ongoing and significant reduction in fat mass and improved whole-body insulin sensitivity, myocardial triglyceride levels fall below baseline levels. This suggests that ongoing weight loss enables MTGC to be utilised by the heart, and hence intracellular levels are able to normalise despite ongoing circulating FFA excess.

The normalisation of MTGC is associated with improvements in both systolic and diastolic function, with $E / e^{\prime}$ improving to a level which is both lower than baseline, and similar to normal weight controls. Interestingly, the cohort remains obese in terms of fat mass and BMI after the VLCD intervention, but myocardial energetics and MTGC have returned to normal levels. This, together with the deterioration at 1 week despite weight loss, is consistent with the hypothesis that the energetic and functional impairment seen in obesity may be driven by altered cardiac metabolism. The fall in MTGC despite increased circulating FFAs also suggests that the myocardium may be increasing oxidative capacity for FAs by 8 weeks. As peroxisome proliferator-activated receptor alpha (PPAR- $\alpha$ ) is the primary regulator of FA oxidation in the heart [28], and has paradoxically been shown to have a blunted response to FAs in obesity [29], one hypothesis is that increased PPAR$\alpha$ activity in response to improved insulin resistance and reduced fat mass, is responsible for the decrease in MTGC seen here. It is also interesting to note that despite the echocardiographic evidence of improved diastolic function, BNP levels in fact rise by a small but significant proportion, in keeping with the likely effect of fat mass reduction on BNP metabolism [21].

In summary, after 8 weeks of VLCD, there are continued metabolic improvements accompanied by ongoing reductions in body fat. Despite initial increase in myocardial fat and deterioration in cardiovascular function, by the end of the VLCD, myocardial energy metabolism and diastolic function return to normal. As the cardiac dysfunction is both early and transient, it seems unlikely that it would result in any long-term cardiovascular risk.

\section{Conclusions}

Although VLCDs produce profound and rapid improvements in insulin resistance and hepatic steatosis, they are associated with an early but significant deterioration in cardiac function, metabolism, and aortic elasticity. This impairment is transient, and with a full 8-week programme, improvements in cardiovascular function become evident. Hence, we demonstrate for the first time, that they represent an exciting potential therapeutic strategy for the treatment of obesity-related heart disease.

Acknowledgements JJR is funded by a British Heart Foundation Clinical Research Training Fellowship (FS/14/54/30946). SN and OJR acknowledge support from the Oxford British Heart Foundation Centre of Research Excellence and the Oxford National Institute for Health Research Biomedical Research Centre.

Author contributions JJR, OJR, and JWT were involved in study conception and design. JJR, MAP, and I Abdesselam were involved in data collection and analysis. I Akoumianakis, NA, and CA were involved in data analysis. JJR drafted the manuscript, and all authors were involved in reviewing and editing the final paper.

\section{Compliance with ethical standards}

Conflict of interest The authors declare that they have no conflict of interest.

Open Access This article is licensed under a Creative Commons Attribution 4.0 International License, which permits use, sharing, adaptation, distribution and reproduction in any medium or format, as long as you give appropriate credit to the original author(s) and the source, provide a link to the Creative Commons license, and indicate if changes were made. The images or other third party material in this article are included in the article's Creative Commons license, unless indicated otherwise in a credit line to the material. If material is not included in the article's Creative Commons license and your intended use is not permitted by statutory regulation or exceeds the permitted use, you will need to obtain permission directly from the copyright holder. To view a copy of this license, visit http://creativecommons. org/licenses/by/4.0/.

\section{References}

1. Sours HE, Frattali VP, Brand CD, Feldman RA, Forbes AL, Swanson RC, et al. Sudden death associated with very low calorie weight reduction regimens. Am J Clin Nutr. 1981;34:453-61.

2. Leslie WS, Ford I, Sattar N, Hollingsworth KG, Adamson A, Sniehotta FF, et al. The Diabetes Remission Clinical Trial (DiRECT): protocol for a cluster randomised trial. BMC Fam Pract. 2016;17:20.

3. Viljanen AP, Iozzo P, Borra R, Kankaanpaa M, Karmi A, Lautamaki R, et al. Effect of weight loss on liver free fatty acid uptake and hepatic insulin resistance. J Clin Endocrinol Metab. 2009;94:50-5.

4. Kirk E, Reeds DN, Finck BN, Mayurranjan SM, Patterson BW, Klein S. Dietary fat and carbohydrates differentially alter insulin sensitivity during caloric restriction. Gastroenterology. 2009;136:1552-60.

5. Lean ME, Leslie WS, Barnes AC, Brosnahan N, Thom G, McCombie L, et al. Primary care-led weight management for remission of type 2 diabetes (DiRECT): an open-label, clusterrandomised trial. Lancet. 2018;391:541-51.

6. Rider OJ, Francis JM, Ali MK, Petersen SE, Robinson M, Robson $\mathrm{MD}$, et al. Beneficial cardiovascular effects of bariatric surgical 
and dietary weight loss in obesity. J Am Coll Cardiol. 2009;54:718-26.

7. Rider OJ, Holloway CJ, Emmanuel Y, Bloch E, Clarke K, Neubauer S. Increasing plasma free fatty acids in healthy subjects induces aortic distensibility changes seen in obesity. Circ Cardiovasc Imaging. 2012;5:367-75.

8. Hexeberg S, Hessevik I, Hexeberg E. Intravenous lipid infusion results in myocardial lipid droplet accumulation combined with reduced myocardial performance in heparinized rabbits. Acta Physiol Scand. 1995;153:159-68.

9. Ge F, Hu C, Hyodo E, Arai K, Zhou S, Lobdell H, et al. Cardiomyocyte triglyceride accumulation and reduced ventricular function in mice with obesity reflect increased long chain fatty acid uptake and de novo fatty acid synthesis. J Obes. 2012;2012:205648.

10. Jonker JT, Djaberi R, van Schinkel LD, Hammer S, Bus MT, Kerpershoek G, et al. Very-low-calorie diet increases myocardial triglyceride content and decreases diastolic left ventricular function in type 2 diabetes with cardiac complications. Diabetes Care. 2014;37:e1-2.

11. Hammer S, van der Meer RW, Lamb HJ, de Boer HH, Bax JJ, de Roos A, et al. Short-term flexibility of myocardial triglycerides and diastolic function in patients with type 2 diabetes mellitus. Am J Physiol Endocrinol Metab. 2008;295:E714-8.

12. Rider OJ, Francis JM, Ali MK, Byrne J, Clarke K, Neubauer S, et al. Determinants of left ventricular mass in obesity: a cardiovascular magnetic resonance study. J Cardiovasc Magn Reson. 2009;11:9.

13. Chirinos JA, Segers P, De Buyzere ML, Kronmal RA, Raja MW, De Bacquer D, et al. Left ventricular mass: allometric scaling, normative values, effect of obesity, and prognostic performance. Hypertension. 2010;56:91-8.

14. Banerjee R, Rial B, Holloway CJ, Lewandowski AJ, Robson MD, Osuchukwu C, et al. Evidence of a direct effect of myocardial steatosis on LV hypertrophy and diastolic dysfunction in adult and adolescent obesity. JACC Cardiovasc Imaging. 2015;8:1468-70.

15. Rial B, Robson MD, Neubauer S, Schneider JE. Rapid quantification of myocardial lipid content in humans using single breathhold ${ }^{1} \mathrm{H}$ MRS at 3 Tesla. Magn Reson Med. 2011;66:619-24.

16. Rayner JJ, Banerjee R, Holloway CJ, Lewis AJM, Peterzan MA, Francis JM, et al. The relative contribution of metabolic and structural abnormalities to diastolic dysfunction in obesity. Int $\mathbf{J}$ Obes. 2018;42:441-7.

17. Banerjee R, Pavlides M, Tunnicliffe EM, Piechnik SK, Sarania N, Philips R, et al. Multiparametric magnetic resonance for the noninvasive diagnosis of liver disease. J Hepatol. 2014;60:69-77.
18. Dutour A, Abdesselam I, Ancel P, Kober F, Mrad G, Darmon P, et al. Exenatide decreases liver fat content and epicardial adipose tissue in patients with obesity and type 2 diabetes: a prospective randomized clinical trial using magnetic resonance imaging and spectroscopy. Diabetes Obes Metab. 2016;18:882-91.

19. Rui L. Energy metabolism in the liver. Compr Physiol. 2014;4:177-97.

20. Kerr M, Dodd MS, Heather LC. The 'Goldilocks zone' of fatty acid metabolism; to ensure that the relationship with cardiac function is just right. Clin Sci (Lond). 2017;131:2079-94.

21. Mehra MR, Uber PA, Park MH, Scott RL, Ventura HO, Harris BC, et al. Obesity and suppressed B-type natriuretic peptide levels in heart failure. J Am Coll Cardiol. 2004;43:1590-5.

22. Peterson LR, Herrero P, Schechtman KB, Racette SB, Waggoner $\mathrm{AD}$, Kisrieva-Ware Z, et al. Effect of obesity and insulin resistance on myocardial substrate metabolism and efficiency in young women. Circulation. 2004;109:2191-6.

23. Carvajal K, Balderas-Villalobos J, Bello-Sanchez MD, PhillipsFarfan B, Molina-Munoz T, Aldana-Quintero H, et al. $\mathrm{Ca}(2+)$ mishandling and cardiac dysfunction in obesity and insulin resistance: role of oxidative stress. Cell Calcium. 2014;56: 408-15.

24. Vincent HK, Powers SK, Stewart DJ, Shanely RA, Demirel H, Naito H. Obesity is associated with increased myocardial oxidative stress. Int J Obes Relat Metab Disord. 1999;23:67-74.

25. Zhou YT, Grayburn P, Karim A, Shimabukuro M, Higa M, Baetens D, et al. Lipotoxic heart disease in obese rats: implications for human obesity. Proc Natl Acad Sci USA. 2000;97: 1784-9.

26. Mizuno Y, Harada E, Nakagawa H, Morikawa Y, Shono M, Kugimiya F, et al. The diabetic heart utilizes ketone bodies as an energy source. Metabolism. 2017;77:65-72.

27. Chinen I, Shimabukuro M, Yamakawa K, Higa N, Matsuzaki T, Noguchi K, et al. Vascular lipotoxicity: endothelial dysfunction via fatty-acid-induced reactive oxygen species overproduction in obese Zucker diabetic fatty rats. Endocrinology. 2007;148: $160-5$.

28. Taegtmeyer H, Golfman L, Sharma S, Razeghi P, van Arsdall M. Linking gene expression to function: metabolic flexibility in the normal and diseased heart. Ann $\mathrm{N} Y$ Acad Sci. 2004;1015:202-13.

29. Young ME, Guthrie PH, Razeghi P, Leighton B, Abbasi S, Patil S, et al. Impaired long-chain fatty acid oxidation and contractile dysfunction in the obese Zucker rat heart. Diabetes. 2002;51:2587-95. 